\title{
INFLUÊNCIA DAS MISSIONÁRIAS PRESBITERIANA NO ENSINO DE ÀLGEBRA E DESENHO DA ESCOLA DOMÉSTICA DE NATAL (1918 - 1924)
}

\section{INFLUENCE OF THE PRESBYTERIAN MISSIONARIES IN TEACHING OF ALGEBRA AND DRAWING OF THE DOMESTIC SCHOOL OF NATAL}

\author{
Maria Maroni Lopes ${ }^{1}$
}

\begin{abstract}
RESUMO
Este texto, que se insere na linha de pesquisa História da Educação Matemática, discute aspectos da influência da missão presbiteriana nas práticas educativas da Escola Doméstica de Natal, especificamente no ensino de álgebra e desenho. Esta era uma instituição de ensino doméstico, modelada segundo o sistema da École Mánagère de Friburgo Suíça, inaugurada em 1914, e funcionando até os dias atuais. Objetivou-se assim, compreender de que modo as irmãs presbiterianas implementaram mudanças no currículo da referida instituição, e que aspectos da álgebra e do desenho estas priorizavam nas abordagens didáticas. Para tanto, analisamos além dos documentos oficiais, os programas de ensino, diários de classe das professoras, e livros didáticos adotados entre 1918 a 1924. O recorte temporal se justifica por ser esse o período que a missionária presbiteriana Leora James esteve à frente da administração da Escola Doméstica. A interpretação dos documentos analisados se deu com base nos argumentos de Saito (2020), Chartier (2010) e Choppin (2011) no tocante a análises de textos históricos, e compreensões a respeito dos livros didáticos. González Astudillo e Sierra Vázquez (2004) colaboram com o nosso entendimento sobre a relevância dos programas de ensino para a construção histórica das instituições educacionais. Evidenciamos, assim, que as irmãs presbiterianas realizaram significativas mudanças no currículo da Escola Doméstica de Natal, inserindo o estudo de álgebra em dois anos de curso, e o desenho ao logo de todo o curso, o qual tinha duração de seis anos. Conclui-se, com isso, que a álgebra fazia parte do grupo de disciplinas que contribuíam com a racionalidade das atividades domésticas e, que mesmo em uma escola voltada a formação feminina os conteúdos estudados em álgebra era os mesmos das escolas para meninos. Não obstante, o desenho se aproximava do estudo de desenho geométrico relacionado as atividades ligadas à ordem prática.
\end{abstract}

Palavras-chave: História da Educação Matemática; Escola Doméstica de Natal; Práticas Educativas.

\begin{abstract}
This text, which is part of the research line known as History of Mathematical Education, discusses aspects of the Presbyterian mission influence on the educational practices of Natal Domestic School, specifically in the teaching of algebra and drawing. This was a home schooling
\end{abstract}

${ }^{1}$ Doutora em Educação Matemática pela Universidade Estadual Paulista (UNESP). Professora vinculada a Universidade Federal do Rio Grande do Norte - UFRN, Caicó, RN, Brasil. Avenida Coronel Martiniano, 1756, Condomínio Victória Vasconcelos, apto 205. Bairro Penedo. CEP: 59300-000. E-mail marolopes@gmail.com

(iD) ORCID iD: https://orcid.org/0000-0002-5487-7022 
Maria Maroni Lopes

Influência das missionárias presbiteriana no ensino de álgebra e desenho da Escola Doméstica de Natal $(1918-1924)$

institution, modeled after the École Mánagère system in Friborg, Switzerland, opened in 1914, and still functioning today. The objective was to understand how the Presbyterian sisters implemented changes in the curriculum of that institution, and what aspects of algebra and design they prioritized in didactic approaches. To this end, we analyzed in addition to the official documents, the teaching programs, class diaries of the teachers, and textbooks adopted between 1918 and 1924. The time frame is justified because this is the period that the Presbyterian missionary Leora James was at the head of the administration of the Domestic School. The interpretation of the analyzed documents was based on the arguments of Saito (2020), Chartier (2010) and Choppin (2011) regarding the analysis of historical texts, and understandings about textbooks. González Astudillo and Sierra Vázquez (2004) collaborate with our understanding of the relevance of teaching programs for the historical construction of educational institutions. Thus, we evidenced that the Presbyterian sisters made significant changes in the curriculum of Natal Domestic School, inserting the study of algebra in two years of course, and the design throughout the entire course, which lasted for six years. It is concluded, therefore, that algebra was part of the group of subjects that contributed to the rationality of domestic activities and that even in a school focused on female education, the contents studied in algebra were the same as in schools for boys. Nevertheless, the drawing approached the study of geometric design related to the activities related to the practical order.

Keywords: History of Mathematics Education; Natal Domestic School; Educational Practices. 
Influência das missionárias presbiteriana no ensino de álgebra e desenho da Escola Doméstica de Natal $(1918-1924)$

\section{Introdução}

Uma rede ampla de sociabilidade foi se estabelecendo no Brasil, ainda no século XIX, com a abertura do país aos estrangeiros, o que culminou em um período de criação de igrejas, escolas, associações de mocidades e escotismos. Nascimento (2007) e Silva (2009) concordam que é nesse período que as missões protestantes norte-americanas se difundiram pelo Brasil, inicialmente se estabelecendo no Rio de Janeiro (capital à época) e São Paulo, e daí para as demais regiões brasileiras. Tiveram seu fortalecimento por meio das igrejas e colégios missionários. Silva e Stamatto (2013) ponderam que a missão presbiteriana norte-americana no Brasil, além da ação evangelizadora, atuava no âmbito da educação e da saúde. Assim, a função de educar estava à cargo das mulheres. Nessa direção, Bastian (1994, p. 130) ressalta que:

\footnotetext{
os pedagogos protestantes foram pioneiros na educação pré-escolar, no ensino técnico (escolas industriais, de artes e ofícios, agrícolas etc), na música, nos esportes e, sobretudo na educação feminina. (...). Entre 1880 e 1920, em toda a América Latina havia escolas e colégios protestantes nas cidades mais importantes fundados principalmente por metodistas, presbiterianos, batistas, congregacionais (BASTIAN, 1994, p. 130).
}

Nessa perspectiva, os presbiterianos chegaram à Pernambuco em duas vertentes, uma ligada à evangelização e outra mais voltada à educação. De modo que, em 1904, a missionária Elisa More Reed, funda em Recife o Colégio Americano de Pernambuco, hoje Colégio Presbiteriano Agnes. Inicialmente, funcionava como escola primária e secundária, para formar meninas, passando depois a ser escola mista. É certo que Pernambuco era referência na região e as discussões e os contatos políticos se davam na capital Recife. É nessa mesma linha que as questões religiosas se aglutinavam no ambiente das escolas, centros e bancos de congregações pernambucanas e se disseminavam nos estados vizinhos, principalmente na Paraíba e no Rio Grande do Norte. Foi durante este período que os missionários presbiterianos se instalaram em Natal, durante o ano de 1896, inicialmente por meio de uma congregação sob a responsabilidade do estado de Pernambuco. Já em 1897 fundaram o Collegio Americano, escola mista de ensino primário e secundário. Com base nos relatórios dos Presidentes dos Estados (1901), 
Influência das missionárias presbiteriana no ensino de álgebra e desenho da Escola Doméstica de Natal $(1918-1924)$

(...) o Collegio Americano que funciona nesta capital sob a direção de Miss Reed, fundado em 1897. Este collegio tem, além de um curso primário bem regulado, um curso secundário de: Portuguez, Inglez (gramática prática), Mathematica (rudimentos) Latim, Historia Geral, Physiologia (rudimentos), Escrita. Exercicios de gymnastica e trabalhos d'agulha para o sexo feminino. (RIO GRANDE DO NORTE, 1901, p. 8)².

Para o curso primário eram ofertadas as seguintes matérias: Primeiras Letras; Exercícios Orais; Língua Inglesa Prática; Aritmética Elementar, Geografia e Caligrafia. O relatório aponta que, no Collegio Americano, a base do aproveitamento é o conhecimento de Aritmética. Observa-se que já existia um grupo de professoras norteamericanas que integravam o corpo docente do Collegio Americano.

Por outro lado, a Escola Doméstica de Natal, instituição não confessional, foi fundada na capital do estado do Rio Grande do Norte, Natal, em 1914, tendo as escolas europeias como modelo. A instituição foi idealizada em 1911 pela Liga de Ensino do Rio Grande do Norte, e teve a implementação de seu projeto três anos depois. A Escola Doméstica é uma instituição voltada para a educação feminina, funcionando até os dias atuais. A inspiração para o currículo inicial da instituição seguia os mesmos princípios do sistema da École Mánagère ${ }^{3}$ de Friburgo (Suíça). A Escola Doméstica de Natal, “[...] foi pioneira no Brasil e América Latina no que diz respeito à organização curricular. Diferenciava-se das demais instituições existentes no país no que se refere a sua proposta de ensino doméstico" (RODRIGUES, 2007, p. 14).

Desse modo, as duas primeiras educadoras da Escola Doméstica são de origem suíça e romena, ambas com formação na mesma École Ménengère de Friburgo. Foram seguidas por norte-americanas, alemãs, irlandesas e francesas. Em nosso estudo, direcionamos o olhar à influência das educadoras norte-americanas, as quais eram ligadas à missão presbiteriana. Discutimos no presente texto aspectos da influência da missão presbiteriana nas práticas educativas da Escola Doméstica de Natal, especificamente no ensino de álgebra e desenho. Objetivamos, assim, compreender de que maneira as irmãs presbiterianas implementaram mudanças no currículo da escola e quais aspectos da álgebra e do desenho priorizavam nas abordagens didáticas. Para tanto, analisamos, além dos documentos oficiais, os manuais didáticos adotados à época, os programas de ensino,

\footnotetext{
${ }^{2}$ Relatório dos presidentes dos estados brasileiros (RN).

${ }^{3} \mathrm{O}$ termo foi traduzido para o português como Escola Doméstica.
} 
Influência das missionárias presbiteriana no ensino de álgebra e desenho da Escola Doméstica de Natal $(1918-1924)$

e registros nos diários de classe das professoras, e em artigos publicados no periódico $A$ Republica.

A análise e interpretação dos documentos se deu com base nos argumentos teóricos de Saito (2020), que nos orienta a tomar como base as três esferas de análises: historiográfica; epistemológica; e contextual. Na esfera historiográfica se faz o estudo crítico das várias formas pelas quais já se analisou o mesmo tema: problemática. No âmbito da interpretação epistemológica da fonte, busca-se compreender a episteme do documento, direcionando o olhar para o interior do texto, na tentativa de entender o que ele nos fornece, ou seja, realiza-se uma crítica textual e teórico-contextual interna. E na esfera contextual, é o momento de um estudo do contexto propriamente histórico, com destaque para as circunstâncias sob quais foi elaborada a fonte em análises.

Para o uso de periódico A Republica como fonte, apoiamo-nos nas concepções de Hernández Díaz (2013, 2016, 2019), Marchão e Henriques (2018). Os referidos autores afirmam que, nas últimas décadas, a imprensa pedagógica assumiu um papel fundamental na produção e estruturação do pensamento pedagógico no âmbito da História da Educação. Ponderam que a sua importância está ancorada às múltiplas possibilidades de investigação em diferentes temáticas no campo educativo, uma vez que aí vamos encontrar muitas informações e opiniões de interesse educativo. Hernández Dias (2013) afirma:

una publicación periódica puede ser considerada como pedagógica de forma específica cuando en su secuencia temporal mantiene um critério de atención y estúdio expresamente interesado en asuntos que afectan a los procesos de la educación, dentro de la instituición escolar o en otras diferentes, pero también educativas y formativas (HERNÁNDEZ DIAS, 2013, p. 16).

Nessa perspectiva, a imprensa pedagógica tem trazido significativas contribuições para a reconstrução e interpretação da História da Educação e da História da Educação Matemática. No caso da influência da missão presbiteriana no ensino de álgebra e desenho da Escola Doméstica de Natal, encontramos diferentes publicações que nos ajudaram a reconstruir e interpretar o seu percurso histórico. 
Influência das missionárias presbiteriana no ensino de álgebra e desenho da Escola Doméstica de Natal $(1918-1924)$

\section{Leora James: presença da missão presbiteriana na Escola Doméstica de Natal}

Como já mencionado, as primeiras dirigentes da Escola Doméstica de Natal foram de origem europeia e norte-americana. Conforme Lopes (2020) e Lima (2004) a vinda de Leora James, graduada pela Columbia University ${ }^{4}$, com experiência em escolas no estado norte-americano da Virginia, para dirigir a escola de Natal se deu por meio do educador Henrique Castriciano5 ${ }^{5}$ A educadora assumiu a direção da instituição em 1918 e se desligou em 1924. Sua estada em Natal coincide com o período de fortalecimento da missão presbiteriana no estado e o crescimento da religião na cidade, com a inauguração da igreja presbiteriana no bairro da Cidade Alta, nas proximidades do histórico bairro da Ribeira.

Logo em 1918, quando passou a administrar a escola, Leora James, solicita a contratação de seis professoras com formação nos Estados Unidos, o que, em nossa interpretação, eram todas ligadas à congregação presbiteriana. Elas eram: Stella Minor, doutora pela Universidade de Missouri, encarregada, antes de vir para o Brasil, pelo governo dos Estados Unidos, de trabalhos especiais de análises químicas no departamento de alimentação. A professora Stella foi contratada para o curso de Economia Doméstica; Elsie Stoltz, graduada pela Escola Normal da Califórnia e pela Universidade da Califórnia e diplomada pela Universidade de Nova York responsável pelo curso de costura, confecções, aritmética, álgebra e geometria. Alice Rivers, diplomada em agricultura pela Escola do Estado da Geórgia, responsável pela parte de jardinagem, leiteria e cursos externos à escola; Lola Stephens, graduada pelo Stockton Business College da California, especialista em trabalhos de escritório, atuava na cadeira de contabilidade, cuidando também dos trabalhos práticos. Rosa James, graduada pela Escola Superior de Rocky Mount, da Carolina do Norte, enfermeira diplomada e registrada no Watts Hospital Carolina do Norte - encarregada dos arranjos internos da Escola Doméstica e de auxiliar

\footnotetext{
${ }^{4}$ A Universidade de Columbia foi fundada em 1754 como King's College pela carta real do rei George II da Inglaterra. É a instituição mais antiga de ensino superior do estado de New York e a quinta mais antiga dos Estados Unidos.

${ }^{5}$ Para maiores informações ler: PINHEIRO, Rosa Aparecida. Educação e modernização em Henrique Castriciano. Natal: EDUFRN, 2005. MARQUES NETO, Cosme Ferreira. Da necessidade de uma "nova" escola só para moças: Henrique Castriciano de Souza e a modernidade pedagógica norte-riograndense (1911 - 1923). Dissertação (Mestrado em História) - Universidade Federal de Campina Grande - UFCG.
} 
Influência das missionárias presbiteriana no ensino de álgebra e desenho da Escola Doméstica de Natal $(1918-1924)$

do curso de puericultura; e finalmente, Moud Latckow, exímia violinista, diplomada pela Universidade de Chicago, admitida para aulas de música.

Quanto à influência das educadoras norte-americanas no programa de ensino da instituição, constatamos que estas fizeram adaptações e mudanças significativas. De modo que o curso completo que era de quatro anos passou para seis anos, tendo dois anos de ensino preparatório e quatro de ensino doméstico e curso técnico secundário, ao qual a escola se destinava. Estabeleceram rotinas de estudos com elevados padrões acadêmicos e impulsionaram parcerias com as famílias tendo como perspectiva a contribuição destas na educação das filhas. A faixa etária de ingresso na escola mudou de 15 para 11 anos, mantendo as alunas inicialmente no curso preparatório.

É nesse período que o programa de algumas disciplinas consideradas da área intelectual passou por adaptações, assim como as de ordem prática que se aproximaram aos costumes e experiências da cultura norte-americana. No que se refere às disciplinas intelectuais, observamos que foi durante a administração de Leora James que o currículo de matemática sofreu algumas modificações. Até 1918 o programa de ensino da escola contava somente com a cadeira de Aritmética, mas após adaptações, passou a contar, também, com as cadeiras de Geometria, Álgebra e Desenho. Assim, as cadeiras de Álgebra, Geometria e Desenho foram implantadas, sendo o ensino de Desenho ministrado nos dois anos do curso preparatório e ao longo de todo o ensino doméstico, ou seja, nos seis anos de curso. Fortaleceram o discurso de cientificidade dando ênfase às disciplinas da área intelectual, como Matemática, Física e Química.

Cumpre lembrar que, à época, foram criados cursos de extensão objetivando o diálogo constante com os educadores locais, os quais ofertavam ciclos de palestras e conferências para as discentes contando com membros da Diretoria da Instrução de Ensino, professores da Escola Normal de Natal, do Atheneu Norte-rio-grandense, da Escola Modelo Augusto Severo, e com demais membros da comunidade local. Nessa mesma perspectiva, houve o incentivo para que as alunas da escola publicassem nos periódicos locais - revista Pedagogium e jornal A Republica - publicações estas, que se somava a artigos sobre temáticas diversas, poesias e crônicas, e pesquisas realizadas no âmbito da instituição.

Concluímos, por meio dos documentos analisados, que as educadoras presbiterianas promoveram o intercâmbio das discentes e docentes em Universidades e 
Maria Maroni Lopes

Influência das missionárias presbiteriana no ensino de álgebra e desenho da Escola Doméstica de Natal $(1918-1924)$

escolas nos Estados Unidos, de modo a estudarem por um ano nas referidas instituições de ensino norte-americanas, bem como foi estabelecido o contato com políticos influentes, educadores, escritores, dentro do estado e fora dele.

\section{Ensino de álgebra e Desenho: uma visada nos programas de ensino, livros didáticos e diários de classe das docentes}

\section{Programas de ensino}

Consideramos em nosso estudo que um programa de ensino, assim como o currículo, é um artefato social e cultural, representando as determinações políticas, filosóficas e educacionais tanto de quem o escreve, como de quem o põe em prática. Entendemos, igualmente a González Astudillo e Sierra Vázquez (2004), quando os autores ponderam que do ponto de vista histórico o programa de ensino é um elemento cultural reflexo da manipulação social que privilegia conteúdos e práticas educativas em detrimento de outras, com finalidades explicitas ou não. Nessa perspectiva, qualquer discurso sobre programa de ensino e, de modo mais amplo, a cultura escolar faz-se necessário para pensar o projeto social que se objetiva construir. Desse modo, com o entrelaçamento das fontes analisadas, elaboramos duas tabelas, que ressaltam as cadeiras que foram ofertadas na Escola Doméstica de Natal no período de 1918 a 1924 quando estava à frente da instituição a Diretora Leora James e as demais professoras norteamericanas, vinculadas à congregação presbiteriana.

Tabela 1 - Cadeiras do Curso Doméstico da Escola Doméstica de Natal, 1918 a 1924.

\begin{tabular}{l|l}
\hline Primeiro Anno & Segundo Anno \\
\hline Portuguez & Algebra \\
Arithemetica & Portuguez \\
Desenho & Desenho \\
Calligrafia & Calligrafia \\
Historia do Brasil & Historia Universal \\
Geografia & Francez ou Inglez \\
Francez ou Inglez & Cultura Physica \\
Cultura Physica & Cosinha \\
Cosinha & Musica \\
Musica & Agricultura \\
Costura & Leiteria \\
Desenho & Costura \\
& Anatomia e Physiologia \\
\hline
\end{tabular}

Fonte: ESCOLA DOMÉSTICA DE NATAL. Prospecto da Escola Doméstica de Natal. Rio de Janeiro: Typ. do Jornal do Commercio. 1919. (Acervo particular da Escola Domestica de Natal). 
Influência das missionárias presbiteriana no ensino de álgebra e desenho da Escola Doméstica de Natal $(1918-1924)$

Tabela 02 - Cadeiras do Curso Doméstico da Escola Doméstica de Natal, 1918 a 1924.

\begin{tabular}{l|l}
\hline $3^{\circ}$ Anno & $4^{\circ}$ Anno \\
\hline Portuguez & Portuguez \\
Álgebra & Contabilidade \\
Desenho & Desenho \\
Francez ou Inglez & Francez ou Inglez \\
Cultura Physica & Cultura Physica \\
Costura & Costura \\
Musica & Musica \\
Criação & Educação Social \\
Jardinagem & Cosinha Artística \\
Hygiene & Methodologia \\
Lavagem & Economia da casa \\
Puericultura e Medicina Prática & Puericultura e Medicina Prática \\
& Química Alimentar \\
\hline
\end{tabular}

Fonte: ESCOLA DOMÉSTICA DE NATAL. Prospecto da Escola Doméstica de Natal. Rio de Janeiro:

Typ. do Jornal do Commercio. 1919. (Acervo particular da Escola Domestica de Natal).

As tabelas 01 e 02 nos mostram que algumas cadeiras são vistas nos seis anos de curso, como Francês ou Inglês e Português. História era estudado em quatro anos e Geografia em três. Em relação às matemáticas, temos a cadeira de Aritmética no primeiro ano de ensino doméstico e Álgebra no segundo e terceiro. Já o ensino de Desenho era ofertado ao longo de todo curso, desde o preparatório até o quarto ano do curso doméstico. No primeiro ano doméstico eram estudados os seguintes temas na cadeira de álgebra:

Definição de: álgebra; símbolos algébricos e problema. Explanação sobre determinados termos algébricos, tais como: coeficiente; radical; índice do radical. Expressões algébricas: monômios, polinômio. Polinômio homogêneo, quantidades semelhantes. Operações: adição; subtração; multiplicação e divisão. Aplicações práticas.

Para o segundo ano, eram tratadas as seguintes temáticas:

Revisão do conteúdo estudo no primeiro ano, equação do primeiro grau, termos semelhantes, solução de uma equação do primeiro grau, regra geral para solução. Propor problemas práticos envolvendo o máximo possível de questões do conteúdo estudado. Equações do segundo grau: solução de equações do segundo grau; soluções de equações completas. Problemas práticos que despertem o interesse das alunas.

No que se refere ao estudo de desenho, foi possível observar que anterior ao ano de 1918 o currículo apresentava um viés mais voltado ao desenho ornamental, com a proposta de desenho vinculado à arte. Não obstante, tinham uma perspectiva de ordem prática direcionado ao ensino doméstico, à exemplo: desenho ligado a corte e costura, 
Influência das missionárias presbiteriana no ensino de álgebra e desenho da Escola Doméstica de Natal $(1918-1924)$

desenho de flores, desenhos de objetos da casa. Entre 1918 e 1924 se intensificou o estudo de desenho relacionado ao desenho geométrico. Assim sendo, estudava-se:

Em papel liso, com o auxílio de instrumentos: traçar contornos poligonais derivados de outros, conservando a forma e reduzindo as extensões a metade, ao terço, ao quarto, e noção de escalas de redução. Traçar contornos poligonais derivados de outros, conservando a forma e tornando as extensões duplas, triplas, quadruplas, e noções de escalas de ampliação. Representação numérica e gráfica de escalas de redução e de ampliação, segundo uma relação dada. Vários exercícios sobre seu uso. Construir um triângulo, sendo dados: $1^{\circ}$ os três lados; $2^{\circ}$ dois lados e um ângulo por eles formados; $3^{\circ}$ um lado e os dois ângulos adjacentes; $4^{\circ}$ dois lados e o ângulo oposto ao maior deles. O texto traz uma pequena observação, ressaltando que, se o professor resolver estes problemas, destacados anteriormente, mostrará oportunamente que as respectivas construções se aplicam também aos triângulos retângulos e isósceles. Inscrever em círculos de raios dados polígonos estrelados de 5 e 12 lados. Traçar a oval regular, sendo dados: $1^{\circ}$ o eixo maior; $2^{\circ}$ o eixo menor; $3^{\circ}$ os dois eixos. Traçar a elipse, sendo dados: o eixo maior e o eixo menor, por meio de pontos e por movimento contínuo. Traçar a paralela, sendo dados: o foco e a diretriz, por meio de pontos e por meio de pontos e por movimento contínuo. Traçar a hipérbole, sendo dados: o eixo transverso e os focos, por meio de pontos.

Evidenciamos, por meio do diálogo entre as fontes, que houve uma mudança considerável no tocante à proposta do ensino de desenho ao longo do período de 1918 a 1924. A educadora Leora James era quem atuava na escola como professora de desenho, vale destacar que seu currículo ressaltava uma larga experiencia com a cadeira de desenho geométrico.

\section{Manuais didáticos ou livros-textos ${ }^{6}$}

Entendemos que o livro é uma produção humana carregada de intenções e igualmente possui uma estrutura específica, que responde à determinados interesses. Nas palavras de Chartier (2010), é um objeto cultural que difunde ideias, transmite conceitos, condensa conhecimentos. Contém e salvaguarda as marcas de um movimento pedagógico, no que concerne a organização e estruturação dos saberes escolares, as escolhas dos métodos de ensino para conduzir uma matéria ou disciplina escolar (CHOPPIN, 2011). O autor, ao tratar em seu tex to O historiador e o livro escolar, destaca:

\footnotetext{
${ }^{6}$ Em nosso estudo adotamos os dois termos: manuais didáticos ou livros-textos para discutir os conteúdos matemáticos presentes em livros didáticos adotados pela Escola Doméstica de Natal, à época.
} 
os manuais representam para os historiadores uma fonte privilegiada, seja qual for o interesse por questões relativas à educação, à cultura ou às mentalidades, à linguagem às ciências... ou ainda à economia do livro, às técnicas de impressão ou à semiologia da imagem. O manual é, realmente, um objeto complexo dotado de múltiplas funções, a maioria, aliás, totalmente desapercebidas aos olhos dos contemporâneos (CHOPPIN, 2000, p. 13).

Assim, é encantador, e até mesmo fascinante, perceber que cada um de nós tem um olhar, uma interpretação diferenciada a respeito dos livros-textos, dependendo, em sua maioria, do lugar social que cada um ocupa e do contexto educacional ao qual estamos inseridos. Desse modo, corroboramos com as ideias de Choppin, quando o mesmo pondera:

o livro veicula, de maneira mais ou menos sutil, mais ou menos implícita, um sistema de valores morais, religiosos, políticos, uma ideologia que conduz ao grupo social de que ele é a emanação: participa, assim, estreitamente do processo de socialização, de aculturação (até mesmo de doutrinamento) da juventude (CHOPPIN, 2000, p. 13).

Ao ser adotado como recurso pedagógico, propõe modelos de ensino e aprendizagem. Contudo, enquanto objeto produzido, difundido, analisado e aprovado por instituições de ensino, os livros-textos estão sujeitos às limitações estruturais, econômicas, políticas e sociais de cada época.

Deste período destacamos a obra de Antônio Trajano, Algebra Elementar como o manual usado nas aulas de álgebra da escola. A nossa compreensão se dá em virtude do programa de ensino aproximar as abordagens dos conteúdos trabalhados no texto do Professor Trajano. No entanto, fazemos essa interpretação por ter sido o referido autor um dos mais citados nos documentos analisados, bem como nas pesquisas sobre o ensino de álgebra nas primeiras décadas do século XX. O autor se propõe a desenvolver, no citado livro, um curso teórico e prático a respeito da Álgebra Elementar. Para Trajano $(1922)^{7}$, a proposta é abordar a Álgebra por meio de um método inovador, simples, fácil e compreensível a todos os alunos e alunas. A obra inclui, entre outros temas, as equações do segundo grau e progressões.

Inicia o estudo de Álgebra com algumas definições, sendo estas a respeito do que entende por: álgebra, símbolos algébricos, problemas, teorema, sinais algébricos e, apresenta algumas explicações sobre o uso dos sinais algébricos. Recorre às ilustrações

\footnotetext{
${ }^{7}$ Algebra elementar, $8^{\text {a }}$ edição, ano 1922. Autor: Antônio Trajano. Esse foi o livro por nós analisado.
} 
Influência das missionárias presbiteriana no ensino de álgebra e desenho da Escola Doméstica de Natal $(1918-1924)$

como reforço das explicações para, em seguida, tratar de propor exercícios aos estudantes $^{8}$. O que denota como problema são questões do tipo: qual o valor de $\mathrm{a}+4 \mathrm{~b}+$ c, sendo dados os valores de a, b e c. Segue discorrendo a respeito das definições relacionadas aos termos algébricos como: coeficiente, coeficiente numeral, coeficiente literal, expoente, raiz, índice da raiz. Em seguida, apresenta o estudo de Expressões algébricas. Com uma linguagem simples, conceitua monômio e polinômio, abordando mais detalhadamente as operações com monômios e polinômios. Destaca o que denomina de casos da adição de polinômios e intercala as explicações com problemas propostos e sua devida solução.

Outro manual didático por nós analisado que ressaltamos aqui se refere ao texto de Faustino de Oliveira Ribeira Junior, Desenho Geral, o qual aborda noções de desenho linear, desenho geométrico, perspectiva, noções de arquitetura e desenho de molduras, figuras e paisagens.

$\mathrm{Na}$ fala do professor Ribeira Junior, em cidades como São Paulo, o gosto pelas artes se desenvolve consideravelmente, quer seja pela inspiração, admiração ou por sua aplicabilidade na educação. Ele afirma que o desenho é imprescindível desde as mais modestas profissões até os chefes de indústrias e ressalta:

\begin{abstract}
a mulher, em suas diversas ocupações domésticas, nos adornos da casa, na confecção dos vestuários, nos trabalhos de agulha ou de cartonagem, nas prendas domésticas, em suma, não pode dispensar o desenho. Além disso a encantadora arte do desenho, Como a música, constitui hoje o característico de uma boa educação, máxime no sexo feminino. Sob o ponto de vista educativo, o estudo do desenho é de uma vantagem dupla; ao mesmo tempo que concorre para o desenvolvimento da vista e do tato, pode influir de um modo benéfico quanto ao cultivo dos bons sentimentos, tornando-se, conseguintemente, um poderoso auxiliar da educação moral. (RIBEIRO JUNIOR, 1898, p. 3).
\end{abstract}

O texto nos reporta aos preceitos da Escola Doméstica de Natal, às discussões sobre os seus programas de ensino, os quais vão à direção de que as matemáticas estejam ligadas às outras cadeiras estudadas como Corte e Costura, Música, Contabilidade, Economia Doméstica, entre outras.

Ao nos debruçarmos sobre o livro do Professor Ribeiro Junior, tecemos uma breve discussão em relação aos conteúdos abordados em conformidade com o que defendiam as dirigentes da Escola Doméstica. $\mathrm{O}$ autor apresenta inicialmente a diferença entre

\footnotetext{
${ }^{8}$ Usuários do livro, os quais chamam de discípulos.
} 
Influência das missionárias presbiteriana no ensino de álgebra e desenho da Escola Doméstica de Natal $(1918-1924)$

desenho e pintura. Em seguida, conceitua desenho, tratando do desenho geral e desenho linear, fazendo uma diferença entre os dois. O que nos chamou atenção é o fato de o autor traçar uma divisão do desenho linear, que pode ser geométrico e à vista. Define como geométrico quando se recorre ao auxílio de instrumentos, destacando os principais instrumentos comumente utilizados - sendo estes: prancheta; régua; esquadro; compasso; transferidor; dupla-decímetro 9 ; e tira-linhas ${ }^{10}$. No tocante ao desenho à vista, o autor ressalta que este geralmente é usado na cópia de paisagens, de figuras e ornamentos e, desse modo, faz-se necessário a habilidade com o desenho à mão.

Quanto aos diários de classe das professoras, foi possível observar que estas seguiam as mesmas orientações passadas às demais instituições do estado, tratando de detalhar em seus registros de aula o horário que ministravam os conteúdos a serem abordados, quanto tempo demoravam em cada temática, como esta foi discutida em sala e as demonstrações do modo que explicavam e passavam as atividades. A presente dinâmica das supracitadas professoras nos auxiliou compreender que os conteúdos presentes nos diários de classe se aproximavam do que expunham os livros-textos e programas de ensino.

Buscou-se, nesse estudo, eleger os manuais didáticos que trouxeram subsídios para responder alguns dos nossos questionamentos e que estavam em consonância com os nossos objetivos, os quais tiveram um significado marcante na formação das educandas da Escola Doméstica de Natal, no período em que as educadoras norte-americanas estiveram atuando na direção e nas cadeiras de álgebra e desenho.

\section{Considerações Finais}

No presente texto, que se insere no âmbito da História da Educação Matemática, se discutiu sobre a influência das missionárias presbiterianas nas práticas educativas da Escola Doméstica de Natal, o que teve como objetivo entender de que modo as missionárias trouxeram contribuições ao ensino de Álgebra e Desenho na referida instituição. As opções seguidas por nós em escrever sobre o estudo se aproxima do que Chartier (2002) ressalta em relação os desafios na escrita de um livro. Para o autor “[...]

\footnotetext{
${ }^{9}$ Pequena régua dividida em 200 milímetros, que serve para medir linhas retas.

${ }^{10}$ Instrumento formado de duas lâminas de aço (para tinta), ou em forma de lapiseira (para lápis) que serve para traçar linhas.
} 
Influência das missionárias presbiteriana no ensino de álgebra e desenho da Escola Doméstica de Natal $(1918-1924)$

editar um trabalho não deve significar a recuperação desse texto inexistente, mas sim tornar explícito tanto a preferência dada a uma das diversas formas registradas do trabalho quanto às escolhas concernentes à materialidade do texto" (CHARTIER, 2002, p. 41).

Nessa perspectiva, optamos por fazer o diálogo entre as fontes, interpretando-as com base nos argumentos que orientam o nosso estudo, de modo a evidenciar que a chegada das missionárias ao estado do Rio Grande do Norte e o ingresso destas na Escola Doméstica de Natal coincidem com o fortalecimento da missão presbiterianas em Natal e no estado.

Concluímos, assim, que as educadoras presbiterianas realizaram significativas mudanças no currículo da Escola Doméstica de Natal, seja por meio de mudanças no currículo, com a inserção do estudo de Álgebra em dois anos de curso e o Desenho ao logo de todo o curso, o qual tinha duração de seis anos, ou em práticas voltadas aos experimentos, as quais buscavam demonstrar a racionalidade do ensino doméstico. Para tanto, a Álgebra se inseria ao grupo de disciplinas que consideravam como parte intelectual do curso. No que se refere ao desenho, estava ligado à ordem prática. Ao analisarmos os livros didáticos e os programas de ensino compreendemos mesmo em uma escola voltada à formação feminina os conteúdos estudados em Álgebra era os mesmos das escolas para meninos.

\section{Referências}

BASTIAN, J. P. (1994). Protestantismo y modernidad latinoamericana. México: Fondo de Cultura Económica.

CHOPPIN, Alain. "O historiador e o livro escolar". História da Educação n. ${ }^{\circ} 11$ (2002): 5-24.

CHARTIER, Roger. ¿La muerte del libro? 1. ed. Santiago, Chile: LOM Ediciones, 2010.

CHARTIER, Roger. Inscrever e apagar: cultura, escrita e Literatura. Tradução Luzmara Curcino Ferreira. São Paulo: Editora Unesp, 2007.

HERNÁNDEZ DÍAZ. José Maria (ed). Prensa Pedagógica y patrimônio histórico educativo. Salamanca, Edições Universidade de Salamanca, 2013.

HERnANDEZ DIAZ, José Maria. Prensa Pedagógica de Castilla y León 1793 1936. Repositório analítico. 2015. 
Influência das missionárias presbiteriana no ensino de álgebra e desenho da Escola Doméstica de Natal $(1918-1924)$

HERNANDEZ DIAZ, José Maria. Prensa Pedagógica, mujeres, niños, sectores populares y otros fines educativos. Salamanca, Edições Universidade de Salamanca, 2018.

LOPES, Maria Maroni. O ensino de Matemática na Escola Doméstica de Natal: contribuições para um diálogo sobre o papel da mulher Norte-rio-grandense (1911 1961). Tese (Doutorado em Educação Matemática) - Universidade Estadual Paulista, Rio Claro, 2020.

LIMA, Daladier da Cunha. Noilde Ramalho: uma história de amor a educação. Natal: Liga de Ensino RN, 2004.

MARQUES NETO, Cosme Ferreira. Da necessidade de uma "nova" escola só para moças: Henrique Castriciano de Souza e a modernidade pedagógica norte-rio-grandense (1911 - 1923). Dissertação (Mestrado em História) - Universidade Federal de Campina Grande - UFCG. 2016.

NASCIMENTO, Ester Fraga V. C. do. Fontes para a História da Educação: Documentos de Missão presbiteriana dos Estados Unidos. Maceió: EDUFAL.

RODRIGUES, Andréa Gabriel Francelino. Educar para o lar, educar para a vida: cultura escolar e modernidade educacional na Escola Doméstica de Natal (1914-1945). Tese (Doutorado em Educação) - Universidade Federal do Rio Grande do Norte, Natal, 2007

SILVA, Sandra C. da. Educação de papel: a Imprensa Protestante Educando Mulheres. Dissertação de Mestrado. Recife: Universidade Federal de Pernambuco.

SAITO, Fumikazu. Curso de análises historiográficas de textos originais. Formato remoto. PUC - SP, 2020.

PINHEIRO, Rosa Aparecida. Educação e modernização em Henrique Castriciano. Natal: EDUFRN, 2005. 